\title{
Risk Management Lessons from Madoff Fraud
}

\author{
$\begin{array}{lll}\text { P. } \text { Clauss }^{1} & \text { T. Roncalli } & \text { G. Weisang } \\ & \end{array}$
}

${ }^{1}$ ENSAI and CREST, France

${ }^{2}$ Évry University, France

${ }^{3}$ Department of Mathematical Sciences,

Bentley University, MA

AMF, November 12, 2009 


\section{Outline}

Asset Management and Agency Problems

The example of dynamic money market (DMM) funds

Understanding Madoff pre Dec. '08

Performance

Alleged strategy

Testing Madoff's Strategy: Simulations and Backtesting

How Madoff Lost The Capital

A Simple Ponzi Scheme Model in Investment Management

Madoff's default

Impact on Operational Risk Management

Characterization of Madoff's fraud

The Standardized Approach

The Advanced Measurement Approach (AMA)

Implications for Regulators and the Investment Industry 
1. Market risks are taken by investors, not by the fund manager.

2. The fund manager is the only decision maker.

- How may investors have control over the fund manager?

- How can the information asymmetry between the fund manager and investors be reduced?

- Agency Problems 


\section{The example of dynamic money markets}

- The "plausible deniability" hypothesis (Calomiris, 2008) : Estimated subprimes default rate used by the industry $=6 \%$

- We consider a DMM fund described as follows in the information notice :

"Typical investors are interested in investments consistent with a primary emphasis upon preservation of capital while allowing a level of income and total return consistent with prudent investment risk."

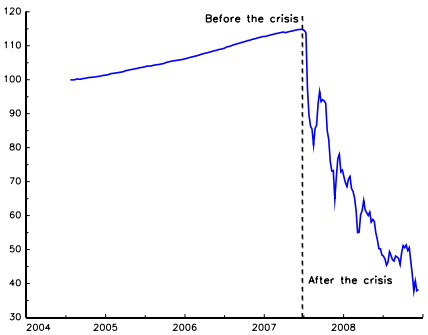

Figure:

Performance of the fund 
Risk Management Lessons from Madoff Fraud

LUnderstanding Madoff pre Dec. '08

LPerformance

Madoff's returns

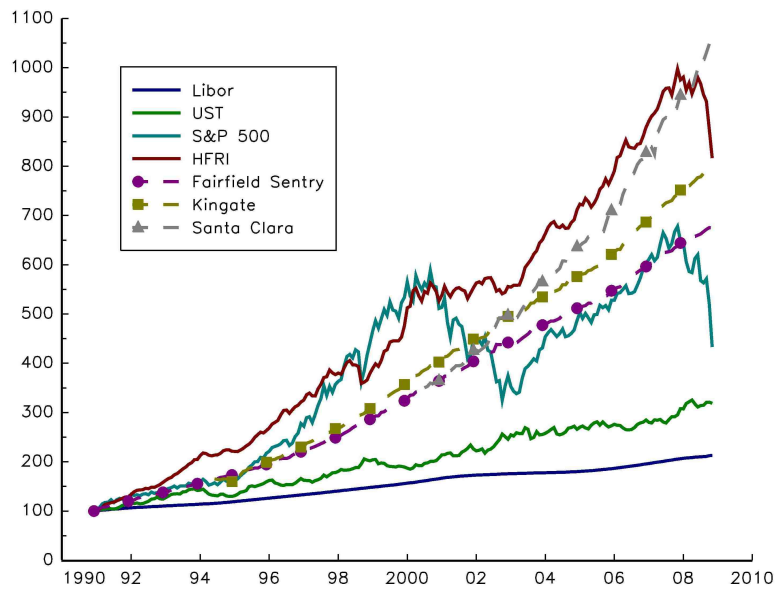

Figure: Comparison of funds invested with Madoff with traditional asset classes 


\section{Statistics of funds invested in Madoff 01/1990 - 10/2008}

\begin{tabular}{c|ccc||cccccc} 
& UST & S\&P 500 & HFRI & FFS & KING & OPTI & SANTA & LUX & HRLD \\
\hline$\hat{\mu}_{1 \mathrm{Y}}$ & 6.68 & 8.52 & 12.42 & 11.24 & 11.56 & 10.96 & 14.19 & 8.29 & 7.27 \\
$\hat{\sigma}_{1 \mathrm{Y}}$ & 6.80 & 14.28 & 7.08 & 3.81 & 4.71 & 2.69 & 4.63 & 1.53 & 1.69 \\
$s$ & 0.33 & 0.28 & 1.10 & 1.75 & 1.47 & 2.48 & 2.26 & 2.73 & 1.87 \\
\hline$\gamma_{1}$ & -0.32 & -0.76 & -0.81 & 4.70 & 6.14 & 0.87 & 1.06 & 0.48 & 0.53 \\
$\gamma_{2}$ & 0.74 & 1.79 & 2.99 & 39.96 & 59.70 & 0.27 & 2.07 & 0.07 & 0.24 \\
\hline$D_{1 \mathrm{M}}$ & -7.09 & -16.80 & -8.70 & -0.55 & -2.30 & -0.39 & -1.87 & -0.19 & -0.37 \\
$D_{3 \mathrm{M}}$ & -8.52 & -23.11 & -13.60 & -0.17 & -4.53 & -0.64 & -1.89 & 0.85 & 0.56 \\
$D_{6 \mathrm{M}}$ & -8.83 & -29.28 & -15.14 & 0.75 & -4.72 & 0.26 & -0.79 & 2.50 & 1.85 \\
$D_{\max }$ & -10.62 & -44.73 & -18.13 & -0.55 & -5.54 & -0.64 & -2.01 & -0.19 & -0.37 \\
\hline$H$ & 64.65 & 64.65 & 73.49 & 93.37 & 92.22 & 91.43 & 74.75 & 98.18 & 88.89
\end{tabular}

- $\hat{\mu}_{1 Y}$ : annualized monthly performance,

- $\hat{\sigma}_{1 Y}$ : yearly volatility,

s: Sharpe ratio,

- $\gamma_{1}$ : skewness,

$-\gamma_{2}$ : excess kurtosis,
$-D_{1 \mathrm{M}}, D_{3 \mathrm{M}}$ and $D_{6 \mathrm{M}}$ : resp. 1,3 and 6 months drawdowns and $D_{\max }$ the maximum drawdown over the entire period.

$-H$ : hit ratio of monthly positive returns.

All statistics are expressed in percents, except for $s, \gamma_{1}$ and $\gamma_{2}$. 
Risk Management Lessons from Madoff Fraud

LUnderstanding Madoff pre Dec. '08

LAlleged strategy

The Bull-Spread strategy a.k.a. Split-Strike Conversion Strategy

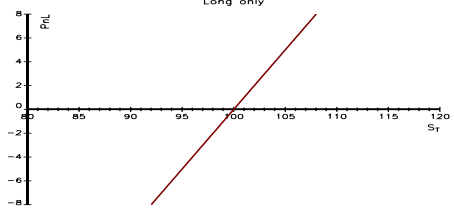

Short Call

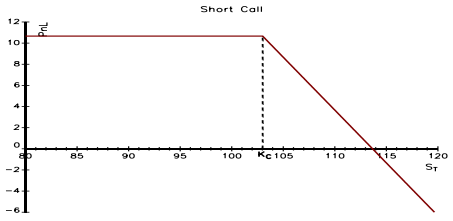

Long Put

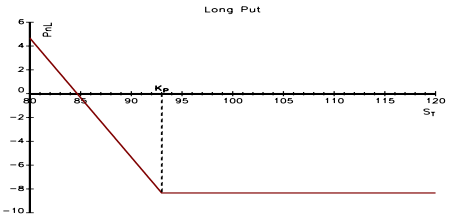

- Bull-Spread strategy

- a long position on $S_{t}$

- a short position on a call option on $S_{t}$, of price $C\left(K_{C}\right)$

- a long position on a put option on $S_{t}$, of price $P\left(K_{P}\right)$

- Payoff function

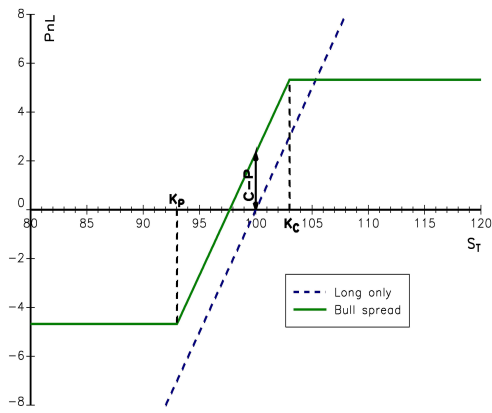


Rationale for BS strategy

- Higher Sharpe Ratios

- lower volatility

- Taking advantage of (left) skew of the distribution of S\&P500 returns

- Stock-picking (alpha)

$$
\begin{aligned}
\operatorname{PnL}_{[0, T]} & =\underbrace{\left(B_{T}-B_{0}\right)}_{\text {Stock Picking }}+\underbrace{C\left(K_{C}\right)-\max \left(0, S_{T}-K_{C}\right)}_{\text {Short Call }} \\
& +\underbrace{\max \left(K_{P}-S_{T}, 0\right)-P\left(K_{P}\right)}_{\text {Long Put }}
\end{aligned}
$$


Testing the BS Strategy

Models

Model 1: Geom. Brownian $\mathrm{d} S_{t}=\mu_{S} S_{t} \mathrm{~d} t+\sigma_{S} S_{t} \mathrm{~d} W_{t}^{S}$

Model 2: Skewed $r_{S}=\ln S_{1}-\ln S_{0}= \begin{cases}\mu_{+}+\sigma_{+} \varepsilon & \text { with prob. } p \\ \mu_{-}+\sigma_{-} \varepsilon & \text { with prob. } q\end{cases}$

with $\varepsilon \sim \mathscr{N}(0,1)$ and $q=1-p$

Model 3: Stock Picking $\mathrm{d} B_{t}=\mu_{B} B_{t} \mathrm{~d} t+\sigma_{B} B_{t} \mathrm{~d} W_{t}^{B}$

$$
\text { with }\left\langle W_{t}^{S}, W_{t}^{B}\right\rangle=\rho \mathrm{d} t
$$


Simulation Results

\begin{tabular}{cc|ccccc} 
& & \multicolumn{5}{|c}{ Sharpe Ratio } \\
\cline { 3 - 6 }$K_{C}$ & $K_{P}$ & Model 1 $^{a}$ & Model 2 $^{b}$ & \multicolumn{3}{c}{ Model 3 } \\
\cline { 3 - 6 } 101 & 99 & 0.265 & 0.328 & 2.319 & 0.594 & 0.290 \\
102 & 98 & 0.263 & 0.325 & 1.795 & 0.660 & 0.310 \\
103 & 97 & 0.260 & 0.322 & 1.481 & 0.729 & 0.330 \\
104 & 96 & 0.258 & 0.319 & 1.276 & 0.801 & 0.351 \\
105 & 95 & 0.255 & 0.316 & 1.132 & 0.872 & 0.371 \\
107 & 93 & 0.251 & 0.310 & 0.947 & 1.005 & 0.411 \\
110 & 90 & 0.244 & 0.300 & 0.792 & 1.136 & 0.470 \\
\hline \hline$\infty$ & 0 & 0.183 & 0.183 & 0.350 & 0.650 & 0.650
\end{tabular}

$$
\begin{aligned}
& { }^{a} \mu_{S}=10 \%, \sigma_{S}=\Sigma=30 \% \\
& { }^{b} p=\frac{2}{3}, \mu_{+}=21.2 \%, \mu_{-}=-25.9 \%, \sigma_{+}=\sigma_{-}=20.2 \% \\
& { }^{c} \rho=1, \mu_{B}=15 \%, \sigma_{B}=30 \% \\
& { }^{d} \rho=1, \mu_{B}=15 \%, \sigma_{B}=20 \% \\
& { }^{e} \rho=0.85, \mu_{B}=15 \%, \sigma_{B}=20 \%
\end{aligned}
$$


Main Results

1. The BS Strategy has a higher Sharpe ratio than the long-only strategy ( $\times 2$ in the most favorable cases).

2. To obtain a Sharpe ratio larger than one, we need a very good stock picking process :

- systematic outperformance with respect to the index;

- perfect correlation with the index. 
Backtesting Madoff's strategy

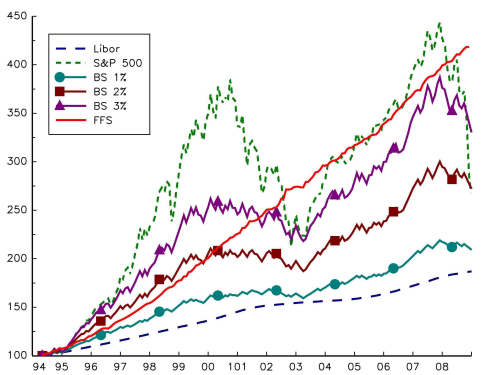

Figure: Backtests of the BS strategy on the S\&P500 index

- High Volatility of the backtests

- To match FFS's volatility, $\kappa=0.65 \% \rightarrow$ Libor's performance

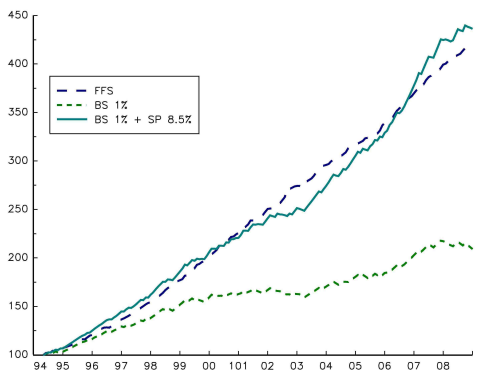

Figure: Introducing stock picking in the BS strategy

- Similar performances, but $30 \%$ more volatility. 
The Ponzi Model

- $K_{t}$ : Capital with return $r_{t}$

- $F_{t}$ : Assets Under Management (AUM) with return $\mu_{t}$

- $K_{t}^{+}=\lambda_{t}^{+} F_{t} \mathrm{~d} t:$ subscriptions

- $K_{t}^{-}=\lambda_{t}^{-} F_{t} \mathrm{~d} t$ : redemptions

- $m_{t}$ : management fees

- Ponzi scheme described by

$$
\left\{\begin{array}{l}
\mathrm{d} K_{t}=r_{t} K_{t} \mathrm{~d} t+\left(\lambda_{t}^{+}-\lambda_{t}^{-}\right) F_{t} \mathrm{~d} t-m_{t} F_{t} \mathrm{~d} t \\
\mathrm{~d} F_{t}=\left(\mu_{t}-m_{t}\right) F_{t} \mathrm{~d} t+\left(\lambda_{t}^{+}-\lambda_{t}^{-}\right) F_{t} \mathrm{~d} t
\end{array}\right.
$$

with $K_{0}=F_{0}$ 
Main Findings

- Management fees are the main contributors to capital shrinkage.

- Default may be avoided only if $m_{t}<\lambda_{t}^{+}-\lambda_{t}^{-}$.

- Default time is a negative function of $m_{t}$ and $\mu_{t}$.

- Higher fees

$\sim$ more capital used to remunerate the fund manager

- Similarly, high $\mu_{t}$

$\sim$ AUM grow more quickly and more fees are generated. 
Estimating net flows rates and amounts

\section{6 feeder funds}

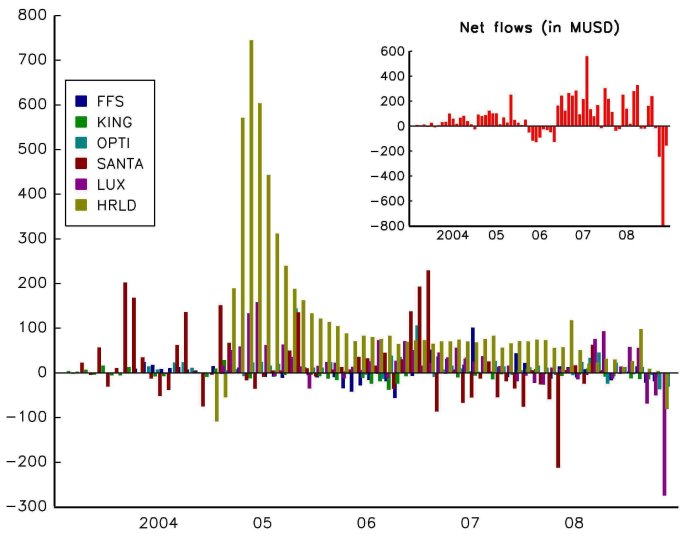

- Fairfield Sentry Ltd (FFS);

- Kingate Global Fund Ltd (KING);

- Optimal Strategic US Equity Ltd (OPTI);

- Santa Clara I Fund (SANTA);

- LuxAlpha Sicav (LUX);

- Herald Fund SPC (HRLD).

Figure: Net flow rates (large graph) and Monthly net flow amounts (top-right graph) 
Explaining the collapse of Madoff Main contributor: LuxAlpha Sicav
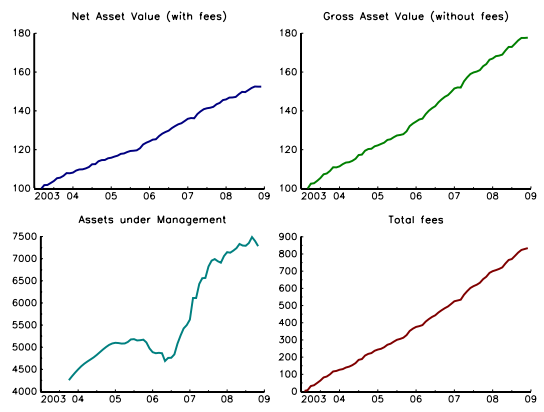

Figure: An example of fees computing

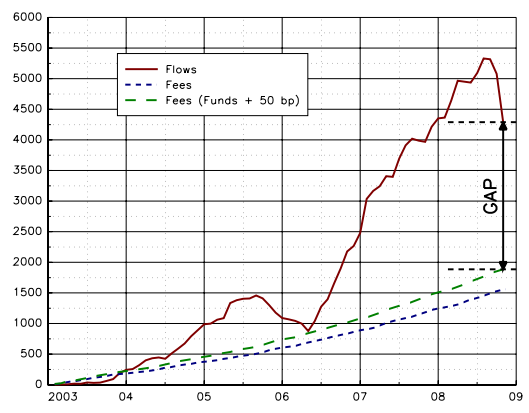

Figure: Estimating the gap in October and November 2008 
Characterization of Madoff's fraud

- For the financial institutions that have launched or distributed Madoff's feeder funds or related products, Madoff's fraud is

- an internal fraud

- an external fraud

- the risk type Clients, Products \& Business Practices: "Losses arising from an unintentional or negligent failure to meet a professional obligation to specific clients (including fiduciary and suitability requirements), or from the nature or design of a product."

- Frauds of this extent are unprecedented for the asset management industry $\Longrightarrow$ What is the impact on operational risk requirements ?

- A new beta in the Standardized Approach ?

- Impact on Advanced Measurement Approach (AMA) 
Definition

Capital Charge $=\beta \times$ Gross Income

\section{Example}

For a gross income of US $\$ 1$ billion, the yearly capital charge for operational risk is US\$ 120 millions.
Table: The SA approach in Basel II

\begin{tabular}{l|c} 
Business Line & $\beta$ factor \\
\hline Corporate finance & $18 \%$ \\
Trading and sales & $18 \%$ \\
Retail banking & $12 \%$ \\
Commercial banking & $15 \%$ \\
Payment and settlement & $18 \%$ \\
Agency services & $15 \%$ \\
Asset management & $12 \%$ \\
Retail brokerage & $12 \%$
\end{tabular}


LDCE 2008

- Asset Management represents 4\% of consolidated gross income (7.7\% for Trading \& Sales).

- Asset Management losses represent 2.5\% of total losses (13.6\% for Trading \& Sales).

- Annual frequency $=704$ losses per year larger than 20000 euros (74\% for the risk type Execution, Delivery, and Process Management and $14 \%$ for the risk type Clients, Products \& Business Practices).

- Annual loss amount $=242.9 \mathrm{ME}$ (53\% for the risk type Execution, Delivery, and Process Management and 31\% for the risk type Clients, Products \& Business Practices).

- The 95th percentile of individual losses is 620000 euros.

$\Longrightarrow$ What would be the impact of Madoff's Fraud? 
Impact of a large loss

- Loss Distribution Approach (LDA)

$$
L=\sum_{n=0}^{N} \ell_{n}
$$

where :

- $L$ is the annual operational risk loss,

- $N$ is the number of next year losses (frequency distribution),

- $\ell_{n}$ are the individual losses (severity distribution).

- The Capital Charge is defined by the $99.9 \%$ percentile of $L$.

- a large loss $\Longrightarrow$ great impact on the severity distribution particularly for low frequency risk type.

- Asset Management (in France) could not support losses greater than $30 \mathrm{ME}$. 
Rethinking Due Diligence Processes

- 4 of the 10 biggest FOHF managers have invested in Madoff's funds.

- Madoff was on the black lists of several banks.

- Operational due diligence versus Quantitative due diligence $\Longrightarrow$ lack of quantitative expertise.

- Initiatives to define a common analysis framework: AIMA, HFWG, etc.

One solution

Product-oriented regulation $\Longrightarrow$ Actor-oriented regulation (the importance of responsibility). 
Rethinking the Hedge Fund industry

- 2003-2007: HF bubble (like the internet bubble).

- 2008-2009: Annus horribilis (liquidity, gates, Madoff, Wearing Capital, K1).

- "Retailization" of the industry.

- Diabolization of the hedge fund industry.

- Promote transparency, liquidity and standardization

- Platform of managed accounts.

- Replication products (carry trades, volatility selling, etc.).

- Benchmark (investable indices) $\Longrightarrow$ first step to build a regulation on hedge funds. 
Impact on Regulations

- The case of LuxAlpha Sicav $\Longrightarrow$ problem of coordination?

- Completing the UCITS III framework ?

\section{Our thinking}

- Keep things very clear for investors.

- A part of the HF industry wants to be regulated.

- Need a specified format and regulation for these hedge funds.

- Create incentives.

- AIFM directive $\Longrightarrow$ Right answer ? 
The AIFM Directive

- Good things

- Regulates unregulated investment products

- Proposes a set of rules (valuation, custody, etc.)

- Systemic risk vs investors protection

- Two main problems

- Wide scope of non UCITS investment vehicles (Private Equity, Hedge Funds, Real-Estate, National regulated funds)

- Very differents in terms of investors, strategies, risks, etc.

- The specific case of private equity (+ Solvency II).

- Too much large and general !

- Ressources and competencies to regulate the industry. 


\section{For Further Reading I}

酒 Carole Bernard, Phelim Boyle.

Mr. Madoff's Amazing Returns: An Analysis of the Split-Strike

Conversion strategy.

Working Paper, 2009.

圂 Charles W. Calomiris.

The Subprime Turmoil: What's Old, What's New, and What's Next.

Working paper presented at the IMF Ninth Jacques Polak Annual

Research Conference, October 2008.

Pierre Clauss, Thierry Roncalli, Guillaume Weisang. Risk Management Lessons From Madoff Fraud. forthcoming in International Finance Review, available on SSRN, 2009. 